\title{
Friendship Preferences Among German and Turkish Preadolescents
}

\author{
Philipp Jugert and Peter Noack \\ Friedrich Schiller University Jena
}

\author{
Adam Rutland \\ University of Kent
}

\begin{abstract}
This study examined changes in and predictors of preference for same-ethnic friendships among German $(N=106)$ and Turkish $(N=45)$ preadolescents $(M$ age $=10.4$ years $)$ during their 1 st year in an ethnically heterogeneous school. Drawing on the contact hypothesis, it examined the relation between children's attitudes and their preference for same-ethnic friendship. Among both German and Turkish children, the latter decreased over time and its variability was predicted by intergroup attitudes and peer norms about crossethnic friendships. Outgroup orientation and perceived contact conditions predicted only German children's preference for same-ethnic friendships. Over time, classroom identification increasingly reduced preference for same-ethnic friendships among Turkish children. The results showed that interindividual attitudes were related to children's level of intergroup contact.
\end{abstract}

Today, schools across Europe are experiencing unprecedented levels of ethnic diversity, which opens up the possibility of cross-ethnic friendships. Research has demonstrated that cross-ethnic friendships result in higher levels of social competence (Eisenberg et al., 2009; Lease \& Blake, 2005), and improved academic motivation and performance (Hallinan \& Williams, 1990). However, research shows that compared to same-ethnic friendships, cross-ethnic friendships are relatively infrequent (Kao \& Joyner, 2004), less stable (Schneider, Dixon, \& Udvari, 2007), and decline with age (Aboud, Mendelson, \& Purdy, 2003). It is important to understand why children seem to prefer same- over cross-ethnic friendships as this may hinder the formation of cross-ethnic friendships. This study examines what attitudes predict children's preference for same- over cross-ethnic friendships. It will also investigate how children's preferences for sameover cross-ethnic friendships in ethnically heterogeneous secondary schools change over the course of their first school year. By following a group of

We thank the schools, parents, and children who made this research possible, and Julian Blanck for help with data collection. We also thank Allard Feddes and Ilka Gleibs for comments on earlier drafts of this article. Preparation of this article was supported by a doctoral fellowship of the Deutsche Forschungsgemeinschaft (GRK 622) awarded to the first author. This article is based on the first author's PhD thesis, and portions of this article were presented at the 15th General Meeting of the European Association of Experimental Social Psychology in Opatija, Croatia.

Correspondence concerning this article should be addressed to Philipp Jugert, Department of Educational Psychology, Friedrich Schiller University Jena, Humboldtstr. 27, 07743 Jena, Germany. Electronic mail may be sent to philipp.jugert@uni-jena.de. preadolescents throughout their 1st year in secondary school, this study examined the trajectories of preference for same-ethnic friendships in this key transition period and explored interindividual differences in preference for same-ethnic friendships.

The present study focused on friendship relations between German (majority status) and Turkish (minority status) children. Turkish people, with systematic immigration to Germany since the early 1960s, are the largest and most visible ethnic minority group in Germany, representing about $3 \%$ of the overall population (Bundesamt, 2008). However, in the city where this study was conducted, almost $7 \%$ of the general population and nearly $13 \%$ of the population under 14 have a Turkish migration background (Landesamt, 2008). Turkish people living in Germany face high levels of discrimination and rejection (Wagner, van Dick, Pettigrew, \& Christ, 2003) and hold considerably lower status in terms of education, health, and employment compared to ethnic Germans (Bundesministerium, 2009). In addition, Turkish children perform worse than their German peers at school (Krohne, Meier, \& Tillmann, 2004), which places them at risk for school dropout and delinquency (Baier \& Pfeiffer, 2008), and severely limits their employment opportunities. Thus, it was assumed in the present study that Turkish children hold a lower social status position than German children (cf. Feddes, Noack, \& Rutland, 2009).

(C) 2011 The Authors

Child Development (c) 2011 Society for Research in Child Development, Inc. All rights reserved. 0009-3920/2011/8203-0008

DOI: $10.1111 / j .1467-8624.2010 .01528 . x$ 


\section{The Context of the Present Study}

We were specifically interested in the development of preference for same-ethnic friendships in a new group, in which most children would not know each other and new friendships were likely to emerge. This was possible in the German school system as children do not always go to the same secondary school as their classmates in elementary school. In fact, children are allocated to secondary schools based upon their grade point average at the end of elementary school so most secondary schools include children from many different elementary schools and neighborhoods. In this context, we decided to use a definition of friendship that is not limited to just best friends but includes good and "OK" friends, too. This assessment of friendship was necessary as a limitation to only best friendships would have been overly restrictive in a context of children entering their 1st year of secondary school in Germany.

The contact conditions in the schools used in the present study were largely very positive. All school principals and teachers were committed to promoting multiculturalism and integrating an ethnically diverse student body. This was evident from school curricula stressing acceptance of diversity and tolerance toward different cultural values and from signs in corridors and classrooms promoting fairness and tolerance. In addition, all schools offered Turkish language courses for both first and second language learners and projects that entail cooperative learning methods. Finally, the children in our study all attended the same academic ability track (i.e., were judged to be at a similar academic level), which makes it more likely that they held equal status in the contact situation. We note, however, that contact conditions might be interpreted differently across groups depending on their social status (Tropp \& Prenovost, 2008). This is why we chose to study subjective perceptions of contact conditions rather than assuming that contact conditions were optimal.

\section{Longitudinal Trajectory of Cross-Ethnic Friendships in Childhood}

Studies comparing same- and cross-ethnic friendships have consistently found a preference for same- over cross-ethnic friendships among children as young as 3 years (Aboud et al., 2003; Boulton \& Smith, 1996; Fishbein \& Imai, 1993; Graham \& Cohen, 1997; Hamm, Brown, \& Heck, 2005; Kao \& Joyner, 2004). Apart from being more seldom than same-ethnic friendships, cross-ethnic friendships seem to be primarily school based and rarely extend beyond the school context (Aboud \& Amato, 2001; Fletcher, Rollins, \& Nickerson, 2004).

There are two alternative predictions that can be made regarding the trajectory of preference for same-ethnic friendships over the 1st year of secondary school. Either preference for same-ethnic friendships should increase as cross-ethnic friendships have been shown to decline with age (Aboud et al., 2003; Graham \& Cohen, 1997) and to be less stable relative to same-ethnic friendships (Schneider et al., 2007). Alternatively, preference for same-ethnic friendships could decrease as preadolescents initially use ethnicity as a criterion for friendship but then once they become more familiar with their classmates use other criteria (e.g., activity preferences). Indeed, research by McGlothlin and colleagues (Margie, Killen, Sinno, \& McGlothlin, 2005; McGlothlin \& Killen, 2005; McGlothlin, Killen, \& Edmonds, 2005) has shown that children in ethnically diverse schools focus more on similarity in activity interests than on ethnicity when judging friendship potential. Given the dearth of research on longitudinal trends in cross-ethnic friendships, both predictions regarding the trajectory of preference for same-ethnic friendships (i.e., up or down) seemed equally likely among ethnic majority and minority children.

\section{Predictors of Preference for Same-Ethnic Friendships}

Cross-ethnic friendships are one form of contact between children from different social groups (i.e., intergroup contact). Extensive research based upon Allport's (1954) contact hypothesis has shown a strong relation between intergroup contact and children's attitudes (Aboud et al., 2003; Cameron, Rutland, Brown, \& Douch, 2006; Feddes et al., 2009; McGlothlin \& Killen, 2006; McGlothlin et al., 2005; Rutland, Cameron, Bennett, \& Ferrell, 2005; Turner, Hewstone, \& Voci, 2007). However, a major limitation of previous research has been its reliance on correlational data (Brown \& Hewstone, 2005; Pettigrew, 1998) and its exclusive focus on attitudes as a dependent variable. Esses and Dovidio (2002) correctly state that "we know a great deal about what happens when different group members come into contact but we know little about the conditions likely to promote intergroup contact in the first place" (p. 1212).

Recent longitudinal adult research (Binder et al., 2009; Eller \& Abrams, 2003, 2004; Levin, van Laar, \& Sidanius, 2003) has shown that attitudes significantly 
influence the formation of cross-group friendships. Research with children also suggests that attitudes affect cross-group friendships. For example, Aboud et al. (2003) found prejudiced ethnic majority children were more likely to exclude cross-ethnic peers. Another study found majority and minority status adolescents with strong ingroup preferences were less likely to nominate cross-ethnic peers as friends (Hamm et al., 2005).

\section{Intergroup Attitudes}

Based upon Allport's (1954) contact hypothesis and the earlier-mentioned research, we predict that positive intergroup attitudes among both German and Turkish children will be related to less preference for same-ethnic friendships. In the present study, we included two measures of children's intergroup attitudes. First, we assessed children's explicit affective attitudes toward their ingroup and outgroup. This type of measure is typical of intergroup contact research that has examined Allport's hypothesis (e.g., Turner et al., 2007). Second, we also measured children's outgroup orientation. Outgroup orientation refers to the strength of one's willingness and the value one attaches, to spending time with people from groups other than one's own (Molina, Wittig, \& Giang, 2004). The research on acculturation suggests that outgroup orientation should be an important predictor of the extent to which people seek contact with other groups (Berry, 1997).

\section{Peer Norms Supportive of Cross-Ethnic Friendships}

Developmental research shows that contact between children from different ethic groups is related to children's understanding of social norms about having cross-ethnic friendship (Feddes et al., 2009; Turner, Hewstone, Voci, \& Vonofakou, 2008). Adolescents' interpretation of parental norms about cross-ethnic relationships is related to their level of interethnic contact (Edmonds \& Killen, 2009). However, developmentally, children are also known to become more sensitive toward which types of behavior are sanctioned by their peers (Abrams, Rutland, \& Cameron, 2003). Indeed, several studies suggest that children's intergroup attitudes are regulated by perceived peer norms (Nesdale, Griffith, Durkin, \& Maass, 2005; Nesdale, Maass, Durkin, \& Griffith, 2005; Rutland, Cameron, Milne, \& McGeorge, 2005).

Other studies have shown that the effect of both direct and indirect contact on children's intergroup attitudes is partially mediated by perceived peer norms (Cameron, Rutland, \& Hossain, 2007; Feddes et al., 2009; Turner et al., 2008). Further, Aboud and Sankar (2007) provided initial qualitative evidence that negative ingroup peer norms prohibiting crossethnic mixing hindered cross-group friendships. Together the above research suggests that peer norms about the legitimacy of cross-ethnic friendships will be related to children's preferences for same-ethnic friendships.

\section{Perceptions of Contact Conditions}

Allport (1954) suggested that for intergroup contact to be successful it should entail four optimal conditions: equal status between groups within the situation, common goals, intergroup cooperation, and authority support for contact between groups. Pettigrew (1998) took this point further in stating that if contact was structured in this way friendship potential would be established. Therefore, in the present study, we investigated children's perceptions of whether the optimal conditions of intergroup contact were present in their school class and if these influenced the formation of cross-ethnic friendships.

Most studies on intergroup contact have not directly measured the extent to which individuals perceived the presence of optimal conditions for contact (Molina \& Wittig, 2006). There is some research suggesting that the positive effects of optimal contact conditions are less pronounced among minority status children compared to majority status children (Tropp \& Prenovost, 2008). However, this research did not look into children's subjective perception of contact conditions. The same contact situation (e.g., school) might be perceived quite differently by children from minority and majority status groups. Therefore, in the present study we used a subjective measure of optimal contact conditions and predict that this will be related to children's preference for same-ethnic friendships.

\section{Shared Identity}

Developmental research utilizing the "common ingroup identity" model of intergroup contact (Gaertner, Mann, Murrell, \& Dovidio, 1989), has shown that contact between different social groups is most effective in promoting positive intergroup attitudes when both the ingroup and outgroup are redefined as one superordinate group (e.g., Cameron et al., 2006). From this perspective, shared identity is 
effective because it increases perception of "us" rather than "we" and "them" (Gaertner \& Dovidio, 2000). This research suggests by emphasizing shared characteristics the ethnic divide in friendships might be overcome.

One form of common ingroup identity in a school setting could be the extent to which people identify with their classroom. If the classroom is ethnically heterogeneous, identification with that classroom implies feeling part of one common ingroup despite the ethnic diversity within the class. Consequently, children who identify highly with their classroom should be less likely to prefer same- over cross-ethnic friends. We predict that classroom identification will be equally predictive of majority and minority children's preference for same-ethnic friendships. In addition, we anticipate that it will take time for children to develop classroom identity when starting in a new school, so the relation between classroom identity and less preference for same-ethnic friendships will increase over the school year.

\section{Method}

\section{Sample}

This study was conducted in a midsized town in the northwest of Germany. We selected schools according to the percentage of children with nonGerman passports with the aim to avoid schools with very high or very low levels of ethnic minority children (no official data existed on school ethnic composition). Seventeen fifth-grade classrooms from four lower academic track and three comprehensive (i.e., including all academic tracks) secondary schools took part in the study. The areas of the schools were predominantly working class (low socioeconomic status). Consent forms were sent out to parents, and $76 \%$ of the eligible sample was allowed to participate. In total, 269 children completed the first and second questionnaires, and 245 children completed the third questionnaire. Of these children, 215 children participated in all waves (attrition: 20\%). The children who participated were ethnically diverse: $42 \%$ German, 20\% Turkish, and $38 \%$ other or mixed-ethnic background (e.g., Albanian, Polish, Russian, Arabic, etc.). The percentage of ethnic minority children in the classrooms ranged from $35 \%$ to $70 \%$ $(M=51.88)$.

Our analysis concentrated on German majority and Turkish minority group children because the other groups were small and would not make a meaningful unit of analysis. As we were interested in same- and cross-ethnic friendship selection, we had to exclude children who did not have at least one ingroup and one outgroup classmate to choose as a friend. We also excluded participants who did not participate at the first measurement point because we were interested in the effect of predictors at the beginning of the school year on outcomes at the end of the school year. This resulted in a sample of 151 (106 German, 45 Turkish; 75 boys, 76 girls), of which 92 (63 German, 29 Turkish) children had data for all three waves, 35 (26 German, 9 Turkish) had data for only two waves, and 24 (17 German, 7 Turkish) had data for only one wave. These children were between 9 and 12 years old $(M=10.4, S D=0.62)$ at the beginning of the school year.

\section{Procedure}

Data were collected at the beginning (Time 1), middle (Time 2), and end (Time 3) of the school year. The children completed the questionnaires in their classrooms. Questions were matched to gender and the order of questions referring to ethnic groups was counterbalanced, resulting in four versions of the questionnaire.

\section{Measures}

Friendship choices. Friendship was assessed using a peer-nomination technique adapted from Aboud et al. (2003). Participants had to rate every samesex classmate on a 5 -point scale $(1=$ best friend, $2=$ good friend, $3=O K$ friend, $4=O K$ but not really a friend, $5=$ don't know very well). Each participant received a class list that contained a number associated with each name (e.g., "Girl 1: Tina S."). In the questionnaire, they then had to tick the box on the scale under Girl 1, Girl 2, and so forth. This procedure was necessary because of data protection laws. Dyads that rated each other as best, good, or OK friends were counted as mutual friends. The numbers of reciprocal same- and cross-ethnic friends were calculated for each child. Only nominations to and from Turkish and German children counted. To assess preference for same-ethnic friendships, we used the compositionally invariant odds ratio, $\log O R$, which controls for opportunities present for same- and cross-ethnic contact in classrooms of varying ethnic composition (Moody, 2001; Rodkin, Wilson, \& Ahn, 2007). We calculated $\log O R$ for each German and Turkish child as follows: 


$$
\log O R=\log (A D / B C),
$$

where $A$ is the number of same-ethnic friends, $B$ is the number of cross-ethnic friends, $C$ is the number of same-ethnic peers with whom the child is not friends, and $D$ is the number of cross-ethnic peers with whom the child is not friends. This index has the advantage that it is not mechanically dependent on the varying presence of ingroup and outgroup peers available across classrooms. This was important as we wanted to assess the impact of predictor variables on friendship selection controlling for contact opportunity. The index also combines sameand cross-ethnic friendship selection in one variable and approximately follows a normal distribution.

Intergroup attitudes. We used four items adapted from Turner et al. (2007) to measure children's explicit affective attitudes toward the outgroup (see the Appendix). All items, except for the second item, were rated on a 5-point scale ranging from 1 (not at all, depicted with a feeling face with a downward position) to 5 (very much, depicted with a feeling face with a large smile position). The scale for the second item ranged from 1 (very bad) to 5 (very good) using the same smiley faces to accompany the anchor points. Cronbach's alphas at Times 1,2 , and 3 were $.91, .89$, and .84 for German children, and $.93, .81$, and .84 for Turkish children.

Our second attitude measure was outgroup orientation toward other groups. This was measured with four items taken from Phinney's (1992) Multigroup Ethnic Identity Measure scale (see the Appendix). The items were scored on a 4-point scale ranging from 1 (no, untrue) to 4 (yes, true). Cronbach's alphas at Times 1,2 , and 3 were .86, .91 , and .87 for German children, and $.87, .94$, and .95 for Turkish children.

Peer norms supportive of cross-ethnic friendships. Perceived peer group norms about crossethnic friendships were assessed with four items measuring both perceptions of German and Turkish children's norms (Cameron \& Rutland, 2008). Children were presented with a group of stick people and a flag of Germany next to it and the instructions read: "Here is a group of German boys or girls. Imagine what they think about being friends with Turkish boys or girls." The ethnic labels were printed in bold, and the second label had an arrow attached to it pointing to a single stick person next to a Turkish flag. The children were then asked to assess how many German children would agree with two statements: "It's a good idea for German boys or girls and Turkish boys or girls to be friends." and "I like being friends with Turkish boys or girls." The same procedure was repeated for the perception of Turkish children's norms. The items were scored on a 4-point scale ranging from 1 (none, depicted with an X) to 4 (all, depicted with a large group of stick people). The correlations between perceptions of German and Turkish children's norms' items were high (all $r s>.60$ ), suggesting that both German and Turkish children perceived German and Turkish children's norms about cross-ethnic friendships to be similar (cf. Feddes et al., 2009). Cronbach's alphas at Times 1, 2, and 3 were $.69, .85$, and .82 for German children, and $.82, .82$, and .86 for Turkish children.

Perceptions of optimal contact conditions. We assessed the children's perception of the extent to which Allport (1954) optimal contact conditions were established in their school class using an abbreviated scale by Molina and Wittig (2006) - see the Appendix. The two items assessing acquaintance potential were negatively worded and had very low item-total correlations. We therefore used a combined index of the remaining six items measuring equal treatment, interdependence, and institutional support. The items were scored on a 4-point scale ranging from 1 (no, untrue) to 4 (yes, true). Cronbach's alphas for the scale at Times 1, 2, and 3 were .61, .71, and .69 for German children, and $.58, .62$, and .81 for Turkish children.

Classroom identification. We measured identification with the classroom using four items adapted from Verkuyten (2002) - see the Appendix. Each item was scored on a 5-point scale ranging from not at all to very. Cronbach's alphas at Times 1, 2, and 3 were $.93, .97$, and .96 for German children, and .95, .92 , and .98 for Turkish children.

\section{Analysis}

First, we looked at mean-level changes for all variables at the three time points for German and Turkish children to explore changes over time and differences due to ethnicity. In addition, we tested for interaction effects of time and ethnicity for all variables. Initially, we also included gender as a between-subjects factor. However, analyses did not show any gender effects so all presented analyses are collapsed across gender.

The central goal of this study was to investigate which predictors influenced preference for sameethnic friendships over time. We employed hierarchical linear modeling (HLM; Raudenbush \& Bryk, 2002) using HLM 6 (Raudenbush, Bryk, \& Congdon, 2004) for this task. We decided to model German and Turkish children separately, as 
preliminary analyses suggested that the two groups followed different growth trajectories in preference for same-ethnic friendships. In addition, the two ethnic groups were very unequal in size and a joint analysis would invite direct group comparisons, which may not be warranted given the small sample size of the Turkish group.

In a multilevel model with longitudinal data, Level 1 includes all observations over $n$ points of measurement that are recorded for each person. On Level 2, each person is only included once, and individuals are the unit of analysis. The Level 1 or within-person model estimates the outcome in relation to time and several time-varying predictors. We expressed a linear change model as follows (Singer \& Willet, 2003):

$$
\log O R_{i t}=\pi_{3 i}+\pi_{1 i} \text { Time }_{i t}+e_{i t} .
$$

In this equation, $\log O R_{i t}$ represents preference for same-ethnic friendships for individual $i$ at time $t$. When Time $3=0$ (time was coded as Time $1=-2$, Time $2=-1$, and Time $3=0$ ), $\pi_{3 i}$ represents i's level of preference for same-ethnic friendships at Time 3; $\pi_{1 i}$ represents $i$ 's rate of change. The residual, $e_{i t}$, represents $i$ 's portion of preference for same-ethnic friendships at time $t$ that is not predicted by time. By centering on Time 3, parameters can be interpreted in relation to the end of the school year. The Level 2 model used the individual growth parameters from the Level 1 model as outcomes and allows testing whether individuals vary in initial status, rate of change, or acceleration, and what predicts variation.

$$
\begin{aligned}
& \pi_{3 i}=\beta_{00}+u_{0 i} \\
& \pi_{l i}=\beta_{10}+u_{1 i} .
\end{aligned}
$$

We can write the composite model as follows:

$\log O R_{i t}=\beta_{00}+\beta_{10}$ Time $_{i t}+\left(e_{i t}+u_{0 i}+u_{1 i} *\right.$ Time $)$.

The predictor variables outgroup orientation, peer norms, and affective intergroup attitudes and contact conditions were Time 1 centered (Singer \& Willet, 2003). This means that we included both Time 1 values as well as the deviation of each subsequent time point from that value into the analysis. Thereby we could get an indication of how preference for same-ethnic friendships was associated with both initial value of a predictor at the beginning of the school year and the increment or decrement, at each subsequent point in time, from that initial value (Singer \& Willet, 2003). The predictor variable class identification was grand-mean centered as we were interested in its interaction with time.

\section{Results}

\section{Preliminary Analyses}

Panel attrition and comparison of participants. To test whether the final sample consisting of all participants who completed all three questionnaires $(N=116)$ differed from those who completed only one or two questionnaires, we compared participants who completed only the first questionnaire $(N=35)$ with those who completed all three questionnaires $(N=116)$ on all Time 1 variables (preference for same-ethnic friendships, outgroup orientation, peer norms, affective intergroup attitudes, class identification, and contact conditions). We performed a multivariate analysis of variance (MANOVA) using a 2 (participation: Time 1 vs. all time points) $\times 2$ (ethnicity: German vs. Turkish) between-participants design. The results suggested no significant effects for participation, $F(6,126)=$ $0.57, p=.75, \eta_{\mathrm{p}}{ }^{2}=.03$, or for the Participation $\times$ Ethnicity interaction, $F(6,126)=0.74, p=.62$, $\eta_{\mathrm{p}}{ }^{2}=.03$, on a multivariate level at Time 1. Analysis at the univariate level showed no differences between children who participated at all time points and children who dropped out after Time 1 (all $F_{\mathrm{s}}<2.60$ ).

Likewise, we tested the influence of dropout between Time 2 and Time 3 on all variables at Time 2. Using a MANOVA, we compared those who participated at Time 1 and Time $2(N=17)$ with those who participated at all three time points $(N=116)$. The MANOVA revealed no significant effects for participation, $F(6,113)=0.65, p=.69, \eta_{\mathrm{p}}{ }^{2}=.03$, or for the Participation $\times$ Ethnicity interaction, $F(6$, 113) $=1.30, p=.27, \eta_{\mathrm{p}}{ }^{2}=.06$, on a multivariate level at Time 2. Univariate tests also showed no differences between children who dropped out between Time 2 and Time 3 and those who took part at all time points (all $F \mathrm{~s}<1.80$ ).

Changes of means and correlations over time. Among all children for which complete data were available we conducted a descriptive analysis of change for both outcome (preference for sameethnic friendships) and predictor variables (outgroup orientation, peer norms, affective intergroup attitudes, class identification, and contact conditions). Variables were subjected to a mixed-model analysis of variance (ANOVA) with time as the withinparticipants factor and ethnicity as a between-participants factor. The analysis showed a significant change over time, $F(12,76)=3.58, p<.001$, $\eta_{\mathrm{p}}{ }^{2}=.36$. In addition, a significant main effect of ethnicity was found, $F(6,82)=9.12, p<.001$, $\eta_{\mathrm{p}}{ }^{2}=.40$, and a significant interaction of Time $\times$ 
Ethnicity, $F(12,76)=2.15, p=.05, \eta_{\mathrm{p}}^{2}=.25$. Table 1 displays results from the repeated measures ANOVAs, including all means and standard deviations. Significant main effects of time (as a within-subjects factor) on preference for sameethnic friendships, outgroup orientation, affective intergroup attitudes, and contact conditions indicated that these variables varied depending on measurement point. In addition, we found significant mean-level differences between German and Turkish children for peer norms and affective intergroup attitudes. Turkish children evaluated German children more positively and perceived more positive peer norms than vice versa. We also found interactions between time and ethnicity for preference for same-ethnic friendships and affective intergroup attitudes.

More specifically, the effect of time on preference for same-ethnic friendships was linear, $F(1,87)=$ 10.86, $p<.01, \eta_{\mathrm{p}}{ }^{2}=.11$, suggesting that preference for same-ethnic friendships decreased over time. However, this finding was qualified by a Time $\times$ Ethnicity interaction, $F(1,87)=3.54, p<.10$, $\eta_{\mathrm{p}}{ }^{2}=.04$. Examination of the means in Table 1 suggested that this trend was only linear for the Turkish children, whereas the German children showed a curvilinear trend. German children's preference for same-ethnic friendships actually increased from the beginning to the middle of the school year (albeit not significantly) and then decreased again from the middle to the end of the school year below the level at the beginning of the school year. The effect of time on outgroup orientation was linear, $F(1,87)=10.88, p<.01, \eta_{\mathrm{p}}{ }^{2}=.11$, with outgroup orientation increasing over time. Likewise, the effect of time on affective intergroup attitudes was linear, $F(1,87)=6.94, p<.05, \eta_{\mathrm{p}}{ }^{2}=.07$, but was qualified by a Time $\times$ Ethnicity interaction, $F(1$, $87)=4.99, p<.05, \eta_{\mathrm{p}}{ }^{2}=.05$. Inspection of the means suggested that this effect was linear only for the German but not for the Turkish children. While the former showed a significant increase in positive intergroup attitudes over time, the latter did not. The results for contact conditions indicated a linear effect of time, $F(1,87)=8.75, p<.01, \eta_{\mathrm{p}}{ }^{2}=.09$, suggesting that perceived contact conditions improved over time. In general, these analyses suggested a pattern of change that was different for German and Turkish children.

The cross-sectional correlations between predictors and outcome are presented in Table 2. For German children, outgroup orientation, peer norms, affective intergroup attitudes, and contact conditions were negatively correlated with preference for

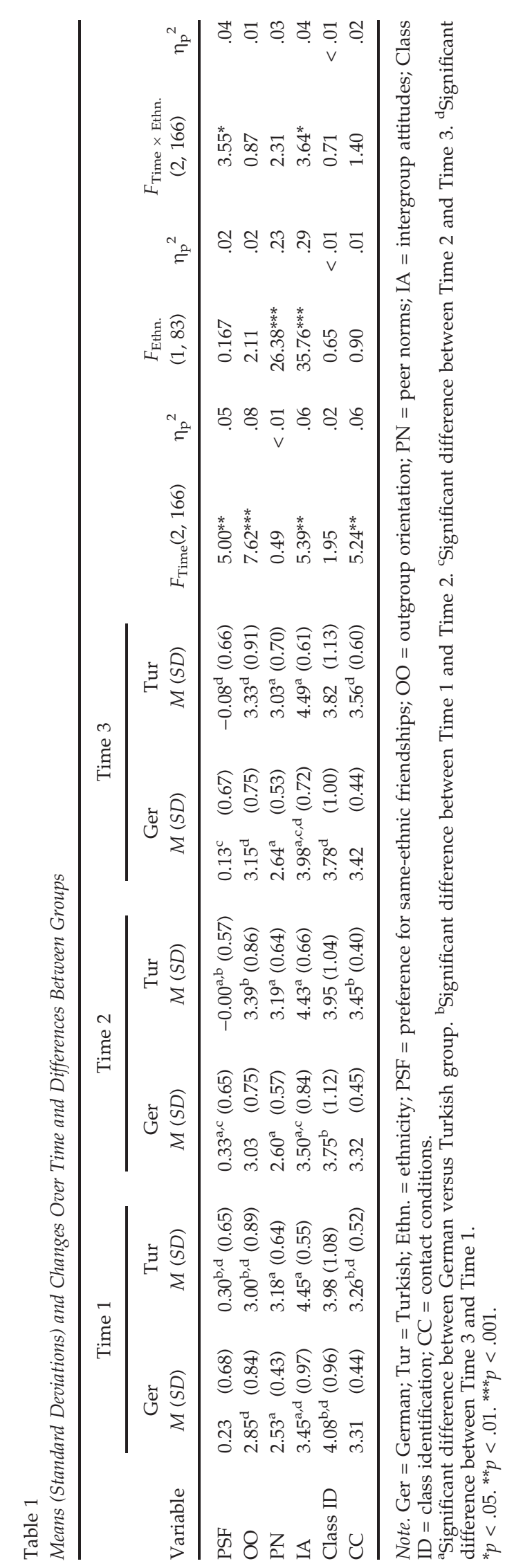




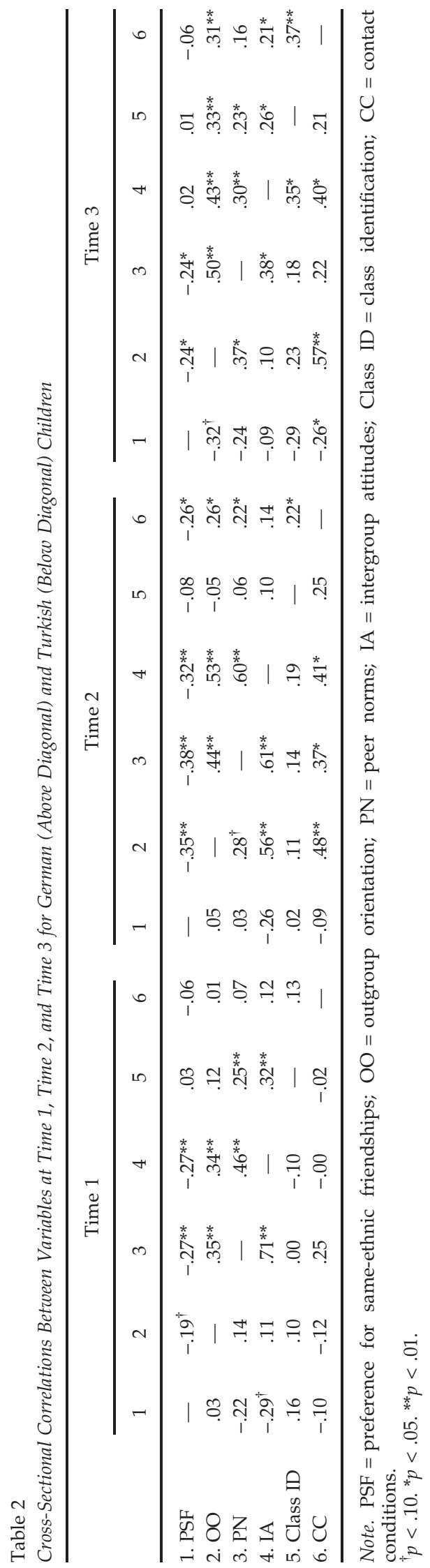

same-ethnic friendships while class identification was not significantly correlated with preference for same-ethnic friendships. It seemed that for affective intergroup attitudes and contact conditions, the correlation with preference for same-ethnic friendships changed over time. For Turkish children, outgroup orientation (marginally), affective intergroup attitudes (marginally), and contact conditions were negatively correlated with preference for sameethnic friendships. Again, class identification was not significantly correlated with preference for same-ethnic friendships and for affective intergroup attitudes and contact conditions the correlation with preference for same-ethnic friendships seemed to change over time.

\section{Multilevel Modeling}

To get further insight into the nature of change in preference for same-ethnic friendships over the school year and to answer the question which predictor variables affected preference for same-ethnic friendships over time, we used a multilevel regression approach (Singer \& Willet, 2003). Time as a factor and the time-varying predictors were included in a Level 1 model and there were no predictors at Level 2. Time-varying predictors were set fixed at Level 2 as we had no reason to suspect random variation within each ethnic group. We also had to set the random effects of time and time ${ }^{2}$ to zero as their variances could not be reliably estimated. Thus, we could not make any inferences about the rate of change or acceleration. The results are presented in Tables 3 and 4 for German and Turkish children, respectively.

\section{Multilevel Model Change of Preference for Same-Ethnic Friends}

First, we fitted an unconditional means model (Model 1). The intercept indicated that the average level of preference for same-ethnic friendships was positive and significantly different from zero across time for German, $b=.21, S E=0.05, t(105)=3.81$, $p<.001$, as well as for Turkish children, $b=.17$, $S E=0.07, t(44)=2.29, p<.05$. The intraclass correlation $\left(\rho=\pi_{00} / \sigma^{2}+\pi_{00}\right)$ suggested that for German children $45 \%$ and for Turkish children $37 \%$ of the variance in preference for same-ethnic friendships were attributable to differences among individuals. We proceeded by testing an unconditional growth model (Model 2) in which we added time (centered at the end of the school year) as a predictor to the model. For German children, the linear trend was 


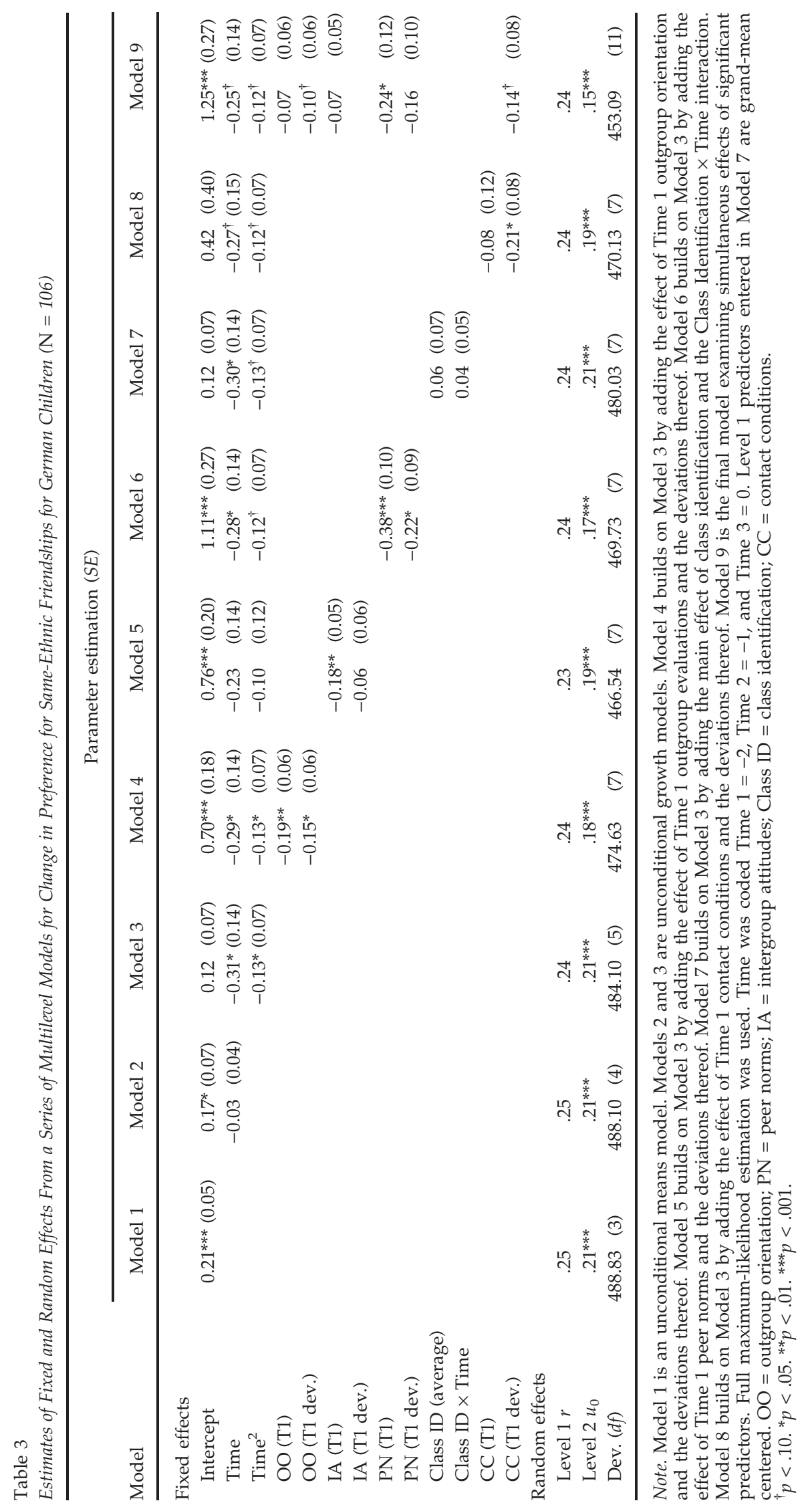




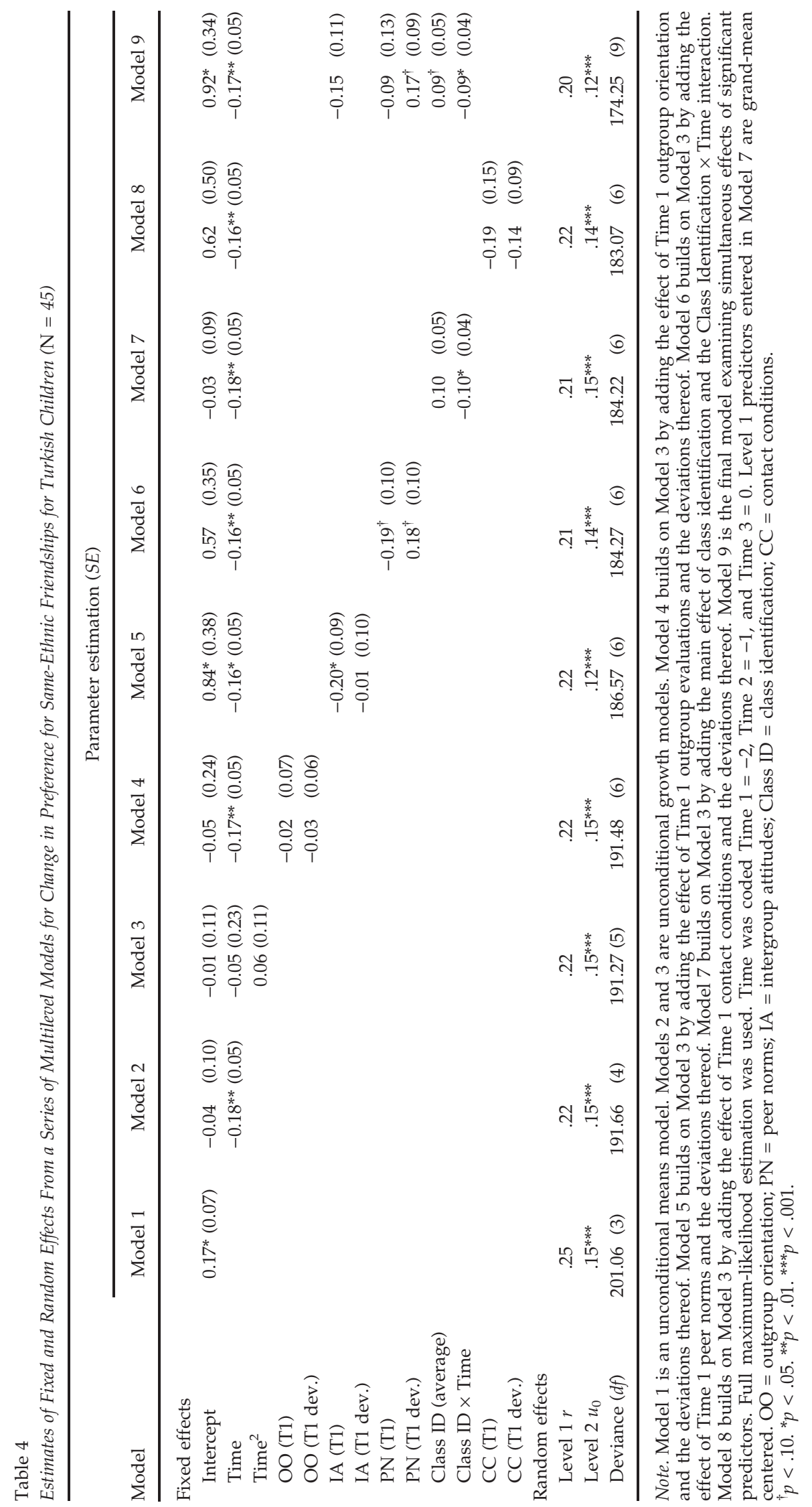


not significant, $b=-.03, S E=0.04, t(256)=-0.86$, $p=.39$, whereas for Turkish children it was, $b=-.18, S E=0.06, t(110)=-3.16, p<.01$. Note that for Turkish children the intercept was not significant after adding the effect of time. This implied that preference for same-ethnic friendships decreased in a linear fashion for Turkish children and they did not show a significant degree of preference for same-ethnic friendships at the end of the school year anymore. We further tested the quadratic effect of time (time ${ }^{2}$ ) on preference for sameethnic friendships in Model 3. Results showed that this parameter was significant for German children, $b=-.13, S E=0.07, t(255)=-1.98, p<.05$, suggesting a quadratic relation between time and preference for same-ethnic friendships. In addition, the intercept was not significant, suggesting that German children's preference for same-ethnic friendships decreased in a curvilinear fashion and was not significant at Time 3 anymore. However, the effect of time ${ }^{2}$ was not significant for Turkish children, $b=.06, S E=0.11, t(109)=0.57, p=.57$. Thus, average change in preference for same-ethnic friendships was linear for Turkish children and quadratic for German children, corresponding to the findings yielded by our analyses of means. In the next models, we moved toward predicting further variability as a function of time-varying predictors to better understand the developmental trends in preference for same-ethnic friendships.

\section{Predicting Preference for Same-Ethnic Friendships}

We tested a series of consecutive models to explore whether trajectories of preference for sameethnic friendships vary over time as a function of the proposed predictors for German and Turkish children. We therefore tested main effects of the predictors on preference for same-ethnic friendships at the end of the school year and, in the case of class identification, also interaction effects with time and time ${ }^{2}$. In Model 4, we included outgroup orientation. The effects of initial value, $b=-.19$, $S E=0.06, \quad t(253)=-3.18, p<.01$, and deviation from that value, $b=-.15, S E=0.06, t(253)=-2.46$, $p<.05$, were both significant for German children. The direction of the effects indicated that outgroup orientation at the beginning of the school year and increases thereof were associated with lower preference for same-ethnic friendships at the end of the year. For Turkish children, both effects were not significant, $b=-.02, \quad S E=0.07, \quad t(108)=-0.34$, $p=.74 ; b=-.03, S E=0.05, t(108)=-0.56, p=.56$, respectively. Thus, German children who scored high on outgroup orientation and whose outgroup orientation increased over the school year showed lower preference for same-ethnic friendships than their German peers who were low in outgroup orientation and whose outgroup orientation did not increase over the school year. Turkish children's outgroup orientation did not seem to influence their preference for same-ethnic friendships.

In Model 5, we tested the effect of affective intergroup attitudes. The results showed that attitudes at the beginning of the year were significantly associated with preference for same-ethnic friendships over time for both German, $b=-.18, S E=0.05$, $t(251)=-3.55, \quad p<.01$, and Turkish children, $b=-.20, \quad S E=0.09, \quad t(108)=-2.32, p<.05$. The direction of the effects suggested that initial attitudes were associated with lower preference for same-ethnic friendships at the end of the year. Deviations from initial attitudes had, however, no significant effect on preference for same-ethnic friendships for either German children, $b=-.06$, $S E=0.06, t(251)=-1.07, p=.28$, or Turkish children, $b=-.01, S E=0.10, t(108)=-0.10, p=.92$. Thus, for both groups initial values in affective intergroup attitudes seemed important in determining the trajectory of preference for same-ethnic friendships while changes in these attitudes over the school year had no measurable impact. So regardless of group status, children with more positive affective intergroup attitudes at the beginning of the school year showed less preference for sameethnic friendships at the end of the school year compared to children with less positive attitudes.

In Model 6, we tested the effect of peer norms. For German children, initial peer norms, $b=-.38$, $S E=0.10, t(253)=-3.65, p<.01$, and changes in norms at subsequent time points, $b=-.22$, $S E=0.09, \quad t(253)=-2.62, p<.05$, had significant effects. The directions of the effects indicated that initial peer norms and subsequent increments in peer norms were associated with lower preference for same-ethnic friendships at Time 3. That is, German children initially high in perceived positive peer norms about cross-ethnic friendships and who showed an increase in these norms over the school year demonstrated less preference for same-ethnic friendships at the end of the school year. For Turkish children, initial peer norms, $b=-.19, S E=0.10$, $t(108)=-1.83, p=.07$, and change in peer norms, $b=.18, S E=0.10, t(108)=-1.82, p=.07$, had marginally significant effects. The direction of the effects suggested that Time 1 peer norms and subsequent decrements in peer norms were associated with lower preference for same-ethnic friendships 
over time. Although the effects were not significant, the effects suggested that Turkish children high in peer norms and whose norms decreased over the school year showed less preference for same-ethnic friendships at the end of the school year.

In Model 7, we tested whether class identification was on average related to preference for sameethnic friendships and whether the effect of class identification would increase over time. For German children, class identification had no significant main effect, $b=.06, S E=0.07, t(252)=0.93, p=.35$, and the Time $\times$ Class Identification interaction was also not significant, $b=.04, S E=0.05, t(252)=0.85$, $p=.39$. To further explore a possible interaction with time, we also included the quadratic effect of time (model not shown) but the Time $\times$ Class Identification interaction, $b=.19, S E=0.12, t(251)=$ $1.55, p=.12$, as well as the Time ${ }^{2} \times$ Class Identification interaction, $b=.07, S E=0.06, t(251)=1.28$, $p=.20$, remained not significant. For Turkish children, the main effect of class identification was not significant, $b=-.10, S E=0.07, t(107)=-1.26$, $p=.21$. However, the Time $\times$ Class Identification interaction was significant, $b=-.10, S E=0.04$, $t(107)=-2.26, p<.05$. This finding indicated that for Turkish children the effect of class identification on preference for same-ethnic friendships became more pronounced over time. As shown in Figure 1, Turkish children who were above average in class identification started to show less preference for same-ethnic friendships between the middle and the end of the school year.

Next, we tested whether initially perceived contact conditions and subsequent changes in these perceptions would affect preference for same-ethnic friendships (Model 8). For German children, initial perceived contact conditions had no significant

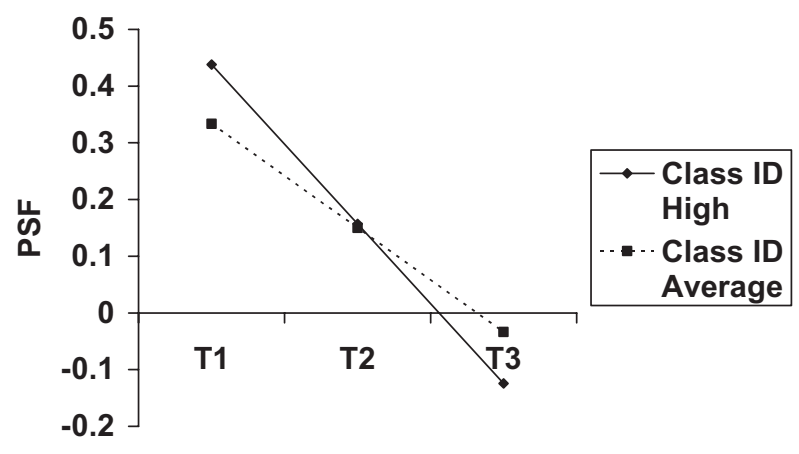

Time

Figure 1. Effects of class identification and time on preference for same-ethnic friends for Turkish children.

Note. PSF $=$ preference for same-ethnic friendships; Class $\mathrm{ID}=$ class identification; $\mathrm{T} 1=$ Time $1 ; \mathrm{T} 2=$ Time $2 ; \mathrm{T} 3=$ Time 3. effect, $b=-.08, S E=0.12, t(249)=-0.69, p=.49$, but subsequent changes in these perceptions had a significant negative effect on preference for sameethnic friendships, $b=-.21, S E=0.08, t(249)=$ $-2.51, p<.05$. These results suggested that while initially perceived contact conditions had no impact on preference for same-ethnic friendships, subsequent increases in these perceptions were associated with lower preference for same-ethnic friendships at the end of the year. For Turkish children, neither initial perceived contact conditions, $b=-.19, \quad S E=0.15, \quad t(105)=-1.29, \quad p=.20$, nor changes thereof had any significant impact, $b=-.14, S E=0.09, t(105)=-1.43, p=.16$.

Finally, we included the significant effects from the previous models into one model to investigate their simultaneous effects (Model 9). It is important to note that some predictors were moderately to highly intercorrelated (e.g., peer norms and affective intergroup attitudes) so that their genuine impact on preference for same-ethnic friendships could not be clearly identified. For German children, only the effect of initial peer norms reached conventional levels of significance, $b=-.24$, $S E=0.12, t(245)=-2.04, p<.05$, when controlling for the effects of outgroup orientation, affective intergroup attitudes, and contact conditions. For Turkish children, only the Time $\times$ Class Identification interaction remained significant, $b=-.09$, $S E=0.04, t(104)=-2.10, p<.05$, when controlling for the effects of affective intergroup attitudes, and peer norms.

\section{Discussion}

Several findings from this study are noteworthy and extend previous work on the formation of cross-ethnic friendships among children. First, we found a general decrease in preference for sameethnic friendships over time, though this preference followed different trajectories for German and Turkish children. Although both groups did not show preference for same-ethnic friendships at the end of the school year, German children showed a curvilinear trend while Turkish children showed a linear trend in preference for same-ethnic friendships. In other words, while this preference decreased among both status groups over time, it decreased at a faster pace among Turkish than among German children. While Turkish children showed strong preference for same-ethnic friendships at the beginning of the year, this preference declined over the year. In contrast, German 
children showed significant preference at the middle of the year caused by a short-lived increase of same-ethnic friends. Second, we were also able to show that factors derived from intergroup contact theory (Allport, 1954) and related research could explain further variability in preference for sameethnic friendships over time. Specifically, we demonstrated longitudinally that trends in children's preferences were linked to affective intergroup attitudes and peer norms for both status groups; while outgroup orientation and contact conditions were only predictive of German children's preferences and the time-varying effect of class identification was only predictive of Turkish children's preferences. We will discuss each finding in turn.

Our finding that preference for same-ethnic friendships generally decreased over time is consistent with the idea that children will prefer sameover cross-ethnic friendships at the beginning of the school year. Then, we found this bias decreased over the school year as children move from unfamiliar to familiar groups and thus other dimensions (e.g., activity preferences) become important for friendship decisions. Our finding thus extends previous work by McGlothlin and colleagues (Margie et al., 2005; McGlothlin \& Killen, 2006; McGlothlin et al., 2005) on friendship potential to actually reported mutual friendships.

This finding is important as it implies that, especially for minority status children, ethnicity becomes less important as a criterion for friendship as children spend more time in ethnically heterogeneous classrooms. Given the largely positive contact conditions in this study, our findings suggest that in such situations minority status children over time may significantly gain from intergroup contact and experience more cross-ethnic friendships (see Binder et al., 2009). By contrast, such advantages for majority status German children appeared to be less sudden since their initial reaction to contact with Turkish children at Time 1 suggests unease or even perceived threat from the minority status group. Previous research has indicated that majority status national groups often perceive minority status national groups as challenging their majority status position in society (Coenders, Gijsberts, Hagendoorn, \& Scheepers, 2004; Scheepers, Gijsberts, \& Coenders, 2002). Some support for this proposition comes from German children's outgroup orientation and affective intergroup attitudes, which only became significantly more positive at Time 3 and not at Time 2. However, over time both majority and minority status children did not show preference for same-ethnic friendships at the end of the school year. It is important to note though that the time frame of the study was limited to the 1st year of secondary school. Thus, it is possible that, with more measurement points, a different picture may have emerged.

One important goal of this study was to identify predictors of preference for same-ethnic friendships based upon intergroup contact theory and to explore whether theses predictors would hold for ethnic majority and minority children. For both German and Turkish children, initial peer norms and changes thereof were important in predicting preference for same-ethnic friendships over time. While the effect of peer norms was particularly strong for German children, it was marginally significant for Turkish children. This finding is original since to our knowledge no previous quantitative study has shown that peer norms also influence actual friendship formation (see Aboud \& Sankar, 2007, for qualitative evidence).

In line with our predictions, initial affective intergroup attitudes at the beginning of the school year predicted both German and Turkish children's levels of preference for same-ethnic friendships at the end of the year. Conversely, subsequent changes in these attitudes were not predictive of preferences for either group. These findings show that initial positive intergroup attitudes are important in determining whether children prefer sameover cross-ethnic friends. Thus, our findings offer some support for previous research conducted with adolescents (Binder et al., 2009) and young adults (Levin et al., 2003). We cannot, however, rule out the reverse effect that preference for same-ethnic friendships also influenced attitudes over the year. Indeed, it is likely that the relation between both constructs is reciprocal.

Contrary to our predictions, outgroup orientation was only predictive of German and not Turkish children's preference for same-ethnic friendships. Turkish children did show equally high levels of outgroup orientation as their German peers and cross-sectionally outgroup orientation correlated negatively with preference for same-ethnic friendships at the end of the school year. However, outgroup orientation is likely to bear different meanings for ethnic majority and minority members (Phinney, Jacoby, \& Silva, 2007). It is possible that for German children openness toward other national groups and willingness to interact with members of these groups is closely associated with friendships with Turkish children because Turkish people are seen as prototypical for "foreigners" living in Germany by ethnic Germans (Asbrock, Lemmer, 
Wagner, Becker, \& Koller, 2008). However, for Turkish children openness toward other national groups might not necessarily mean being open to contact with Germans but being open to contact with any other national group, including other minority status groups (e.g., Russian or Polish).

We had expected that perceived optimal contact conditions would be predictive of children's preference for same-ethnic friendships. This prediction was confirmed for German but not for Turkish children. However, while not significant, the size of the effects for Turkish children indicated that perceived contact conditions were somewhat important in determining Turkish children's preference for same-ethnic friendships. For German children, we found that initially perceived contact conditions did not predict preference for same-ethnic friendships over time while subsequent increases in perceived contact conditions did have predictive power. It is conceivable that contact conditions were hard to assess for the children at the beginning of the school year and only began to make an impact on preferences at subsequent points in time. Nevertheless, it is significant that we showed if children perceive contact conditions to be improving over time then this lowered their preference for same-ethnic friendships. These findings show that it is problematic to assume merely that perceived contact conditions are stable both over time and interindividually (Molina \& Wittig, 2006; Molina et al., 2004) and have a uniform effect on children's friendship choices.

As predicted classroom identification, a form of common ingroup identity had a time-varying effect on preference for same-ethnic friendships. However, this was only true for Turkish children. To explain why classroom identity was only predictive of Turkish children's preference for same-ethnic friendships, it might be useful to consider the different meanings classroom identity might hold for majority and minority status groups in Germany. Turkish children were always a numerical minority in the classrooms compared to German children who were typically a numerical majority. In addition, all teachers were German. For Turkish children, then, classroom identity might have be closely associated with being in a majority German classroom and could thus be a proxy for identifying with the German majority group. Conversely, for German children classroom identity might not have been associated with Turkish children since they were typically in the majority and ethnic identity is generally less salient for ethnic majority children compared to ethnic minority children (Phinney et al., 2007). Therefore, it was likely that for Turkish but not German children classroom identification was psychologically similar to desiring contact and wishing to form friendships with the ethnic outgroup.

\section{Limitations and Suggestions for Further Research}

First, we note that any group differences found have to be treated with caution as the Turkish subsample was very small compared to the German subsample and thus issues of differential power arise. In addition, although we tested for gender effects and did not find any our modest sample size may have masked possible gender effects. Therefore, future research should endeavor to include larger samples to allow for analysis of any possible gender effects. The exclusive focus on German and Turkish children did not entirely reflect the reality of the classroom since the context was multinational. However, the other ethnic groups (e.g., Russians) were relatively small and would not make a meaningful unit of analysis-either separately or combined. A larger sample may have allowed for an examination of preference for same-ethnic friendship among different multiple national groups. It would also be important to see whether similar results would be obtained when looking at out-of-school friendships. However, we are less optimistic here as initial interviews conducted 1 year prior to the current study with a group of fifth graders $(N=16)$ toward the end of the school year indicated that children very seldom met with their cross-ethnic school friends outside of school.

It is worth noting that we used a definition of friendship that included mutual best, good, and OK friends. Similar definitions of friendship have been used in other social networks studies of peer groups (e.g., Baerveldt, Van Duijn, Vermeij, \& Van Hemert, 2004; Burk, Steglich, \& Snijders, 2007), and this definition was appropriate given we were studying preference for same-ethnic friendships during the 1st year of secondary schools in Germany. Nonetheless, different results may have been found using a different definition of friendships within another context.

Future research should include measures regarding children's interpretations of friendship choices. It should examine how children justify why they might not befriend a member of another ethnic group. This would help us understand more about when and how ethnic group membership plays a role in children's friendship choices. Perhaps, more open-ended assessments could shed more light on 
children's reasoning about friendship choices (cf. Killen, Henning, Kelly, Crystal, \& Ruck, 2007). Though our study was concerned with longitudinal trends in preference for same-ethnic friendships and predicting this preference over time, future research could examine the likely consequences of cross-ethnic friendship formation. For example, future studies may also include measures of social competence to assess whether cross-ethnic friendships facilitate children's empathy and perspectivetaking. Ethnic majority children's empathy might increase through sharing the perspective with an ethnic minority friend who might be less well off and a victim of discrimination (Nesdale, Griffith, et al., 2005). Whereas for ethnic minority children, having cross-ethnic friends might open up opportunities to learn social behaviors that are accepted in the majority culture (cf. Eisenberg et al., 2009). Future research might also examine whether crossgroup friendships develop over time and are predicted by similar factors when intergroup contact conditions are less favorable than in this study or there is a history of deep-rooted conflict between groups (e.g., religions, races).

Although we used a longitudinal design, the employed analysis (HLM) does not allow for direct tests of causal direction (Singer \& Willet, 2003). It is possible to combine autoregressive, cross-lagged, and latent growth models to answer simultaneously questions of causal direction, growth, and change over time (e.g., Bollen \& Curran, 2004). However, these hybrid models ideally require five waves of data and large sample sizes throughout. Future studies should be designed such that they provide the possibility to answer simultaneously questions about stability and change as well as growth.

The results of this study suggest some practical implications for educators concerned with how to promote cross-ethnic friendships in the school setting. The powerful effect of perceived peer norms for both status groups implies that practitioners should challenge existing norms that hinder crossethnic friendships. Educators could, for instance, point out existing cross-ethnic friendship pairs in the classroom as positive examples of harmonious intergroup relations. A way of targeting peer norms about friendship more directly could be to use extended contact interventions that work with textbooks featuring friendships between children from different status groups (Cameron \& Rutland, 2006; Cameron et al., 2006; Liebkind \& McAlister, 1999). Importantly, teachers should not shy away from discussing ethnicity with their pupils and should make their attitudes explicit to the children (Aboud \& Doyle, 1996; Katz, 2003; Tatum, 1997).

To conclude, the present study suggests that when German and Turkish children proceed through their 1st year in an ethnically heterogeneous secondary school, their preference for sameethnic over cross-ethnic friends decreases over time. We also showed that factors derived from intergroup contact theory (Allport, 1954) and related research could account for longitudinal variability in preference for same-ethnic friendships. Changes in both majority and minority status children's preference for same-ethnic friendships over time were related to their affective intergroup attitudes and understanding of peer norms about crossethnic friendships. However, we did find differences across status groups regarding some key predictors of same-ethnic preference, namely, desire for and openness to outgroup contact and shared identity. Altogether these results provide an important contribution to the existing literature on cross-ethnic peer relations and will hopefully bring us one step further to understanding under which conditions opportunity for contact may lead to positive intergroup relations in our increasingly diverse schools.

\section{References}

Aboud, F. E., \& Amato, M. (2001). Developmental and socialization influences on intergroup bias. In R. Brown \& S. Gaertner (Eds.), Blackwell handbook of social psychology: Intergroup processes (pp. 65-87). Oxford, UK: Blackwell.

Aboud, F. E., \& Doyle, A. B. (1996). Does talk of race foster prejudice or tolerance in children? Canadian Journal of Behavioural Science/Revue Canadienne des Sciences du Comportement, 28, 161-170.

Aboud, F. E., Mendelson, M. J., \& Purdy, K. T. (2003). Cross-race peer relations and friendship quality. International Journal of Behavioral Development, 27, 165-173.

Aboud, F. E., \& Sankar, J. (2007). Friendship and identity in a language-integrated school. International Journal of Behavioral Development, 31, 445-453.

Abrams, D., Rutland, A., \& Cameron, L. (2003). The development of subjective group dynamics: Children's judgments of normative and deviant in-group and outgroup individuals. Child Development, 74, 1840-1856.

Allport, G. W. (1954). The nature of prejudice. Cambridge, MA: Addison-Wesley.

Asbrock, F., Lemmer, G., Wagner, U., Becker, J., \& Koller, J. (2008). Das Gefühl macht den Unterschied. Emotionen gegenüber "Ausländern" in Ost- und Westdeutschland. In W. Heitmeyer (Ed.), Deutsche Zustände (Vol. 7, pp. 152-167). Frankfurt, Germany: Suhrkamp. 
Baerveldt, C., Van Duijn, M. A. J., Vermeij, L., \& Van Hemert, D. A. (2004). Ethnic boundaries and personal choice. Assessing the influence of individual inclinations to choose intra-ethnic relationships on pupils' networks. Social Networks, 26, 55-74.

Baier, D., \& Pfeiffer, C. (2008). Türkische Kinder und Jugendliche als Täter und Opfer von Gewalt [Turkish children and youth as perpetrators and victims of violence]. In M. Brumlik (Ed.), Ab nach Siberien? Wie gefährlich ist unsere Jugend? [To Siberia? How dangerous are our youth?] (pp. 62-104). Weinheim, Germany: Beltz.

Berry, J. W. (1997). Immigration, acculturation, and adaptation. Applied Psychology: An International Review, 46, 5-34.

Binder, J., Zagefka, H., Brown, R., Funke, F., Kessler, T., Mummendey, A., et al. (2009). Does contact reduce prejudice or does prejudice reduce contact? A longitudinal test of the contact hypothesis among majority and minority groups in three European countries. Journal of Personality and Social Psychology, 96, 843-856.

Bollen, K. A., \& Curran, P. J. (2004). Autoregressive latent trajectory (ALT) models: A synthesis of two traditions. Sociological Methods E Research, 32, 336-383.

Boulton, M. J., \& Smith, P. K. (1996). Liking and peer perceptions among Asian and White British children. Journal of Social and Personal Relationships, 13, 163177.

Brown, R., \& Hewstone, M. (2005). An integrative theory of intergroup contact. In M. P. Zanna (Ed.), Advances in experimental social psychology (Vol. 37, pp. 255-343). San Diego, CA: Elsevier Academic Press.

Bundesamt, S. (2008). Bevölkerung und Erwerbstätigkeit: Bevölkerung mit Migrationshintergrund-Ergebnisse des Mikrozensus 2006. Wiesbaden, Germany: Statistisches Bundesamt.

Bundesministerium, D. I. (2009). Migrationsbericht des Bundesamtes für Migration und Flüchtlinge im Auftrag der Bundesregierung: Migrationsbericht 2007. Retrieved from http://www.bmi.bund.de/cae/servlet/contentblob/ 297624/publicationFile/14808/migrationsbericht_2007. pdf

Burk, W. J., Steglich, C. E. G., \& Snijders, T. A. B. (2007). Beyond dyadic interdependence: Actor-oriented models for co-evolving social networks and individual behaviors. International Journal of Behavioral Development, 31, 397-404.

Cameron, L., \& Rutland, A. (2006). Extended contact through story reading in school: Reducing children's prejudice toward the disabled. Journal of Social Issues, 62, 469-488.

Cameron, L., \& Rutland, A. (2008). An integrative approach to changing children's intergroup attitudes. In S. Levy \& M. Killen (Eds.), Intergroup attitudes and relations in childhood through adulthood (pp. 191-203). New York: Oxford University Press.

Cameron, L., Rutland, A., Brown, R., \& Douch, R. (2006). Changing children's intergroup attitudes toward refu- gees: Testing different models of extended contact. Child Development, 77, 1208-1219.

Cameron, L., Rutland, A., \& Hossain, L. (2007, MayJune). Prejudice-reduction through story-reading: Indirect contact in the classroom. Paper presented at the annual meeting of the Jean Piaget Society, Amsterdam.

Coenders, M., Gijsberts, M., Hagendoorn, L., \& Scheepers, P. (2004). Introduction: Nationalism and exclusionist reactions. In M. Gijsberts, L. Hagendoorn, \& P. Scheepers (Eds.), Nationalism and exclusion of migrants: Cross-national comparisons (pp. 1-25). Aldershot, UK: Ashgate.

Edmonds, C., \& Killen, M. (2009). Do adolescents' perceptions of parental racial attitudes relate to their intergroup contact and cross-race relationships? Group Processes E Intergroup Relations, 12, 5-21.

Eisenberg, N., Sallquist, J., French, D. C., Purwono, U., Suryanti, T. A., \& Pidada, S. (2009). The relations of majority-minority group status and having an otherreligion friend to Indonesian youths' socioemotional functioning. Developmental Psychology, 45, 248-259.

Eller, A., \& Abrams, D. (2003). "Gringos" in Mexico: Cross-sectional and longitudinal effects of language school-promoted contact on intergroup bias. Group Processes $\mathcal{E}$ Intergroup Relations, 6, 55-75.

Eller, A., \& Abrams, D. (2004). Come together: Longitudinal comparisons of Pettigrew's reformulated intergroup contact model and the common ingroup identity model in Anglo-French and Mexican-American contexts. European Journal of Social Psychology, 34, 229-256.

Esses, V. M., \& Dovidio, J. F. (2002). The role of emotions in determining willingness to engage in intergroup contact. Personality and Social Psychology Bulletin, 28, 1202-1214.

Feddes, A. R., Noack, P., \& Rutland, A. (2009). Direct and extended friendship effects on minority and majority children's interethnic attitudes: A longitudinal study. Child Development, 80, 377-390.

Fishbein, H. D., \& Imai, S. (1993). Preschoolers select playmates on the basis of gender and race. Journal of Applied Developmental Psychology, 14, 303-316.

Fletcher, A. C., Rollins, A., \& Nickerson, P. (2004). The extension of school-based inter- and intraracial children's friendships: influences on psychosocial wellbeing. American Journal of Orthopsychiatry, 74, 272-285.

Gaertner, S. L., \& Dovidio, J. F. (2000). Reducing intergroup bias: The common ingroup identity model. New York: Psychology Press.

Gaertner, S. L., Mann, J., Murrell, A., \& Dovidio, J. F. (1989). Reducing intergroup bias: The benefits of recategorization. Journal of Personality and Social Psychology, $57,239-249$.

Graham, J. A., \& Cohen, R. (1997). Race and sex as factors in children's sociometric ratings and friendship choices. Social Development, 6, 355-372.

Hallinan, M. T., \& Williams, R. A. (1990). Students' characteristics and the peer-influence process. Sociology of Education, 63, 122-132. 
Hamm, J. V., Brown, B. B., \& Heck, D. J. (2005). Bridging the ethnic divide: student and school characteristics in African American, Asian-descent, Latino, and White Adolescents" cross-ethnic friend nominations. Journal of Research on Adolescence, 15, 21-46.

Kao, G., \& Joyner, K. (2004). Do race and ethnicity matter among friends? Activities among interracial, interethnic, and intraethnic adolescent friends. Sociological Quarterly, 45, 557-573.

Katz, P. A. (2003). Racists or tolerant multiculturalists? How do they begin? American Psychologist, 58, 897-909.

Killen, M., Henning, A., Kelly, M. C., Crystal, D., \& Ruck, M. (2007). Evaluations of interracial peer encounters by majority and minority U.S. children and adolescents. International Journal of Behavioral Development, 31, 491500.

Krohne, J. A., Meier, U., \& Tillmann, K. J. (2004). Sitzenbleiben, Geschlecht und Migration. Zeitschrift für Pädagogik, 50, 373-391.

Landesamt, S. (2008). Bevölkerung mit Migrationshintergrund nach Migrationsstatus, Geschlecht und Bezugsstaat (nur Stadt Bremen) (17357). Bremen, Germany: Statistisches Landesamt.

Lease, A. M., \& Blake, J. J. (2005). A comparison of majority-race children with and without a minority-race friend. Social Development, 14, 20-41.

Levin, S., van Laar, C., \& Sidanius, J. (2003). The effects of ingroup and outgroup friendship on ethnic attitudes in college: A longitudinal study. Group Processes $\mathcal{E}$ Intergroup Relations, 6, 76-92.

Liebkind, K., \& McAlister, A. L. (1999). Extended contact through peer modelling to promote tolerance in Finland. European Journal of Social Psychology, 29, 765780.

Margie, N. G., Killen, M., Sinno, S., \& McGlothlin, H. (2005). Minority children's intergroup attitudes about peer relationships. British Journal of Developmental Psychology, 23, 251-269.

McGlothlin, H., \& Killen, M. (2005). Children's perceptions of intergroup and intragroup similarity and the role of social experience. Journal of Applied Developmental Psychology, 26, 680-698.

McGlothlin, H., \& Killen, M. (2006). Intergroup attitudes of European American children attending ethnically homogeneous schools. Child Development, 77, 13751386.

McGlothlin, H., Killen, M., \& Edmonds, C. (2005). European-American children's intergroup attitudes about peer relationships. British Journal of Developmental Psychology, 23, 227-249.

Molina, L. E., \& Wittig, M. A. (2006). Relative importance of contact conditions in explaining prejudice reduction in a classroom context: Separate and equal? Journal of Social Issues, 62, 489-509.

Molina, L. E., Wittig, M. A., \& Giang, M. T. (2004). Mutual acculturation and social categorization: A comparison of two perspectives on intergroup bias. Group Processes E Intergroup Relations, 7, 239-265.
Moody, J. (2001). Race, school integration, and friendship segregation in America. American Journal of Sociology, 107, 679-716.

Nesdale, D., Griffith, J., Durkin, K., \& Maass, A. (2005). Empathy, group norms and children's ethnic attitudes. Journal of Applied Developmental Psychology, 26, 623-637.

Nesdale, D., Maass, A., Durkin, K., \& Griffith, J. (2005). Group norms, threat, and children's racial prejudice. Child Development, 76, 652-663.

Pettigrew, T. F. (1998). Intergroup contact theory. Annual Review of Psychology, 49, 65-85.

Phinney, J. S. (1992). The multigroup ethnic identity measure: A new scale for use with diverse groups. Journal of Adolescent Research, 7, 156-176.

Phinney, J. S., Jacoby, B., \& Silva, C. (2007). Positive intergroup attitudes: The role of ethnic identity. International Journal of Behavioral Development, 31, 478-490.

Raudenbush, S. W., \& Bryk, A. S. (2002). Hierarchical linear models: Applications and data analysis methods. Thousand Oaks, CA: Sage.

Raudenbush, S. W., Bryk, A. S., \& Congdon, R. (2004). Hierarchical linear and nonlinear modeling (Version 6.06). Lincolnwood, IL: Scientific Software International.

Rodkin, P. C., Wilson, T., \& Ahn, H.-J. (2007). Social integration between African American and European American children in majority Black, majority White, and multicultural elementary classrooms. In P. C. Rodkin \& L. D. Hanish (Eds.), Social network analysis and children's peer relationships. New directions for child and adolescent development (Vol. 118, pp. 25-42). San Francisco: Jossey-Bass.

Rutland, A., Cameron, L., Bennett, L., \& Ferrell, J. (2005). Interracial contact and racial constancy: A multi-site study of racial intergroup bias in 3-5 year old AngloBritish children. Journal of Applied Developmental Psychology, 26, 699-713.

Rutland, A., Cameron, L., Milne, A., \& McGeorge, P. (2005). Social norms and self-presentation: Children's implicit and explicit intergroup attitudes. Child Development, 76, 451-466.

Scheepers, P., Gijsberts, M., \& Coenders, M. (2002). Ethnic exclusionism in European countries. Public opposition to civil rights for legal immigrants as a response to perceived ethnic threat. European Sociological Review, 18, 17-34.

Schneider, B. H., Dixon, K., \& Udvari, S. (2007). Closeness and competition in the inter-ethnic and co-ethnic friendships of early adolescents in Toronto and Montreal. Journal of Early Adolescence, 27, 115-138.

Singer, J. D., \& Willet, J. B. (2003). Applied longitudinal data analysis: Modelling change and event occurrence. New York: Oxford University Press.

Tatum, B. D. (1997). Why are all the Black kids sitting together in the cafeteria? New York: Basic Books.

Tropp, L. R., \& Prenovost, M. A. (2008). The role of intergroup contact in predicting children's inter-ethnic attitudes: Evidence from meta-analytic and field studies. In S. Levy \& M. Killen (Eds.), Intergroup 
relations: An integrative developmental and social psychological perspective (pp. 236-248). New York: Oxford University Press.

Turner, R. N., Hewstone, M., \& Voci, A. (2007). Reducing explicit and implicit outgroup prejudice via direct and extended contact: The mediating role of self-disclosure and intergroup anxiety. Journal of Personality and Social Psychology, 93, 369-388.

Turner, R. N., Hewstone, M., Voci, A., \& Vonofakou, C. (2008). A test of the extended intergroup contact hypothesis: The mediating role of intergroup anxiety, perceived ingroup and outgroup norms, and inclusion of the outgroup in the self. Journal of Personality and Social Psychology, 95, 843-860.

Verkuyten, M. (2002). Ethnic attitudes among minority and majority children: The role of ethnic identification, peer group victimization and parents. Social Development, 11, 558-570.

Wagner, U., van Dick, R., Pettigrew, T. F., \& Christ, O. (2003). Ethnic prejudice in East and West Germany: The explanatory power of intergroup contact. Group Processes \& Intergroup Relations, 6, 22-36.

\section{Appendix}

Affective Intergroup Attitudes Items (Adapted From Turner et al., 2007)

1. "How much do you like Germans/Turks?"

2. "What do you feel toward Germans/Turks?"

3. "How nice are Germans/Turks?"

4. "How much do you trust Germans/Turks?"

The Four Items From Phinney's (1992) Multigroup Ethnic Identity Measure Scale

1. "I like meeting and getting to know people from a different country other than my own."

2. "I often spend time with people from a different country other than my own."
3. "I am involved in activities with people from a different country other than my own."

4. "I enjoy being around people from a different country other than my own."

Items Used to Measure Children's Perceptions of Allport's (1954) Optimal Contact

Conditions-Abbreviation of the Scale by Molina and Wittig (2006)

Equal treatment: "In this class the teacher is fair to all children no matter what country they are from," "All children in this class are treated equal no matter what country they are from."

Interdependence: "In this class children from different countries all work together for the same things," "In this class children from different countries work well together on group tasks."

Acquaintance potential: "In this class I talk to students from different countries only when I have to," "In this class children from different countries just don't like being together."

Authority support: "In this class the teacher encourages children to make friends with children from other countries," "In this class one is encouraged to be friends with everybody."

The Four Items Used to Measure Identification With the Classroom Adapted From Verkuyten (2002)

1. "How much do you like being part of this class?"

2. "How proud are you to be part of this class?"

3. "How happy are to be part of this class?"

4. "How glad do you feel about being part of this class?" 